\title{
O Turismo de Negócios e Eventos em Cascavel (Paraná, Brasil): oportunidade para expansão e consolidação do segmento na cidade
}

\section{The Business and Events Tourism in Cascavel (Paraná, Brazil): opportunity to expansion and consolidation of the segment in the city}

\author{
Carlos Alberto Schulze (SCHULZE, C. A.) ${ }^{*}$
}

\begin{abstract}
RESUMO - Essa pesquisa objetiva identificar uma oportunidade de expansão e consolidação no setor de turismo na cidade de Cascavel (Paraná, Brasil), com foco no segmento de negócios e eventos, visto que a cidade realiza eventos variados de repercussão nacional e internacional e que, a cada ano, têm seu público aumentado movimentando, assim, uma ampla gama de serviços da economia local e regional. Cascavel se destaca como polo regional econômico do Paraná no setor do agronegócio, educação, saúde, situando-se no oeste do estado e localiza-se próxima a pontos turísticos importantes como Cataratas do Iguaçu e Usina Hidrelétrica de Itaipu, alvo de visitação de grande número de turistas do Brasil e mundo, o que lhe oferece oportunidades de destaque no Turismo sob um prisma distinto do que vem ocorrendo no município até então. A metodologia utilizada foi de pesquisa bibliográfica e eletrônica que contêm definições, informações econômico-sociais do município, repercussão e dados econômicos dos eventos realizados na cidade. Como resultado foi possível perceber uma nova estratégia de atuação de empresas locais e foco de investimentos do setor público.
\end{abstract}

Palavras-chave: Negócios; Eventos; Turismo; Oportunidade; Cascavel/PR.

ABSTRACT - This research aims to identify an opportunity of expansion and consolidation in the tourism sector in Cascavel/ PR, focusing on business and events segment, as the city holds several events of national and international repercussion and, every year, have increased its audience, moving this way a wide range of services from local and regional economy. Currently the city is known as regional economic hub of Paraná and it is a reference in agribusiness sector, education, health, it is situated in the west of the state and is located close to major attractions such as Iguassu Falls and Hydroelectric Power Plant of Itaipu, target of a large number of tourists from Brazil and the other countries, which offers outstanding opportunities in tourism from an angle different from what have been happening in the city so far. The methodology used was the literature and electronics search that contain definitions, social and economic information of the city, and economic data repercussions of the events held in the city. As a result it was possible to realize a new business strategy and focus of investments of local businesses and public sector.

Key words: Business; Events; Tourism; Opportunity; Cascavel/PR.

\footnotetext{
* Graduação em Turismo (Bacharelado) pela Universidade do Oeste do Paraná (UNIOESTE), campus Foz do Iguaçu/PR. Especialista em estratégias empresariais pela União Educacional de Cascavel (Univel). Consultor de Empresas e bolsista do Conselho Nacional de Desenvolvimento Científico e Tecnológico (CNPq) no projeto NAGI - Núcleo de Apoio à Gestão da Inovação. Endereço para correspondência: Rua Marcelino Meneguzzi, 648. CEP: 85805-170 - Cascavel - Paraná (Brasil). Telefone: 45-8422-7656. Email: carlos.schulze@yahoo.com.br
} 


\section{INTRODUÇAO}

A cidade de Cascavel, localizada no oeste paranaense, conta com 286.205 habitantes conforme censo de 2010 do IBGE - Instituto Brasileiro de Geografia e Estatística, sendo o quinto município mais populoso do estado do Paraná, destacando-se como polo econômico regional nas áreas de medicina, educação, comércio e agronegócio (CASCAVEL, 2012b; IBGE 2010).

Diante disso, a presente pesquisa tem como finalidade abordar o Turismo em seu contexto amplo e busca ressaltar o segmento de negócios e eventos, o qual movimenta bilhões de reais no Brasil (MINISTÉRIO DO TURISMO, 2010a), como uma inovadora oportunidade de mercado para a cidade de Cascavel, aproveitando o potencial já existente no município que atualmente recebe grandes eventos, como feiras e encontros de diversas áreas.

A cidade detém, ainda, a consolidação da posição de epicentro do Mercado Comum do Sul - MERCOSUL devido sua localização geográfica estratégica (CASCAVEL B, 2012b), destacando-se com a realização grandes eventos como os encontros do setor do agronegócio, a exemplo do Show Rural Coopavel e Expovel, do setor comercial como Fercalce - Feira Regional de Calçados e Acessórios Esportivos e Fecom - Feira de Comércio Varejista e ainda, em 2012 foram realizados dois grandes eventos do automobilismo como uma etapa da Fórmula Truck, Stockcar e o Moto1000 GP. (CASCAVEL, 2012b)

Contudo, observa-se que a infraestrutura local responsável pela recepção, estada e atendimento dos turistas durante os dias de tais eventos, são insuficientes ou poderiam ser melhoradas a fim de proporcionar um maior nível de qualidade levando o turista ou visitante a sentir-se acolhido pelo local (CASCAVEL, 2012b; SEMDEC, 2012), motivado a permanecer por mais tempo e disposto a retornar em outras oportunidades. Além disso, buscar superar suas expectativas, de forma que em sua memória fiquem experiências positivas de atendimento, organização, hospitalidade e agilidade ao realizar ou participar de um evento na cidade.

Dessa forma, obter-se-ia não somente uma imagem positiva de Cascavel quanto à realização de eventos, mas proporcionaria um crescimento econômico considerável, por meio de geração de empregos ligados ao setor que mais cresce no Brasil atualmente 
e que tem levado o país a um nível internacional na organização e sedição de grandes eventos (GUIA DO ESTUDANTE 2012; MINISTERIO DO TURISMO, 2010a), a exemplo da copa do mundo a ser realizada no ano de 2014 e as olimpíadas no ano de 2016, conferindo, também, uma possibilidade inovadora de investimento, visto que a economia local é calcada no agronegócio e terceiro setor (CASCAVEL, 2012b).

O Turismo é atualmente uma importante atividade econômica em várias regiões do país, sendo que o Brasil é o principal destino do mercado turístico internacional na América do Sul ocupando o segundo lugar na América Latina em fluxo de visitantes internacionais (OMT, 2003). Conforme publicação do ministério do turismo com dados de 2010, 96\% dos turistas manifestaram o interesse de retornar ao Brasil, ratificando o país como um importante destino no cenário mundial e com expectativas de crescimento no futuro (MINISTERIO DO TURISMO, 2010a).

Neste contexto, o estado do Paraná recebe 13 milhões de pessoas ao ano e cada uma delas gasta aproximadamente 62 dólares por dia de estada usufruindo dos recursos que a infraestrutura turística lhes proporciona, conforme o plano de ações 2011/2014 da SETU - Secretaria Estadual de Turismo do Estado - SETU (2011). Assim, Cascavel sendo a quinta maior cidade do estado em população, e por meio da organização de grandes eventos e por sua localização próxima a um dos maiores atrativos turísticos do Brasil, as Cataratas do Iguaçu, é possível explorar ainda mais este setor que tanto cresce e contribui para o desenvolvimento econômico das regiões onde ocorre.

\section{EMBASAMENTO TEÓRICO}

A pesquisa se utilizou de relatórios estatísticos sobre o Turismo no estado do Paraná e do Brasil, sua influência na economia do país e do estado, além de notícias de âmbito local com informações da cidade de Cascavel e os eventos nela realizados. Com essas informações foram interpretados os dados e levantadas oportunidades de negócio para o segmento do turismo de negócios e eventos na cidade de Cascavel. 


\subsection{A CIDADE DE CASCAVEL}

Conhecida como capital do oeste, metrópole do MERCOSUL (CASCAVEL, 2012b B) e do futuro (CASCAVEL, 2012a A) a cidade foi ocupada inicialmente pelos espanhóis em 1557 quando fundaram a Ciudad Real Guayrá, atualmente município de Guaíra, distante $150 \mathrm{~km}$ da cidade e, a partir, das décadas de 30 e 40 por colonos sulistas descendentes de alemães, poloneses, italianos, ucranianos e caboclos, vindos das regiões cafeeiras que iniciaram a exploração de madeira, prática da agricultura e criação de suínos no povoado que viria se tornar distrito em 1938. (CASCAVEL, 2012b).

O município foi emancipado em 14 de novembro de 1951, durante os ciclos econômicos da erva-mate e da madeira que se esgotaram na década de 1970 e, logo após esse período, deu-se o início da industrialização na cidade com a instalação de empresas do ramo de confecção e metalurgia, concomitantemente com o aumento da atividade agropecuária, fazendo surgir o agronegócio que atualmente tem grande destaque na economia municipal. (CASCAVEL, 2012b).

O nome da cidade é de origem histórica e remonta aos indígenas e colonos conforme abaixo:

O termo "cascavel" origina-se de uma variação do latim clássico "caccabus",
cujo significado é "borbulhar d'água fervendo". Segundo a lenda, o nome
surgiu de um grupo de colonos que, pernoitando nos arredores de um rio,
descobriram um grande ninho de cobras cascavéis, denominando então o
local como "Cascavel". A sonoridade do guizo originou o nome da serpente:
do latim "tintinnabulum", literalmente "o badalar do chocalho". Símbolo de
poder e sabedoria, a serpente era cultuada na antiguidade. (CASCAVEL,
2012b).

Atualmente a cidade tem um perfil jovem, contando aproximadamente com 21 mil acadêmicos distribuídos em sete instituições de ensino superior sendo, também, referência na medicina e na prestação de serviços. (CASCAVEL, 2012b). Segundo a mesma fonte o setor avícola, tem ganhado destaque devido aos dois milhões de aves abatidas diariamente nos frigoríficos da cidade. A força da indústria, dos serviços prestados e a economia local pujante vêm conferindo à cidade um crescimento econômico anual e populacional, a exemplo da taxa de $16,76 \%$ registrada no período de 2000 a 2010 (IBGE, 2010). 
Um dos fatores que tem facilitado o fortalecimento econômico é sua estratégica posição geográfica, pois se localiza em um entroncamento rodoviário e é ponto de passagem para os estados de Santa Catarina, São Paulo, Mato Grosso do Sul e Mato Grosso, importantes portos do litoral e, também, a outros países como Paraguai e Argentina. Na figura abaixo, pode-se visualizar essa posição:

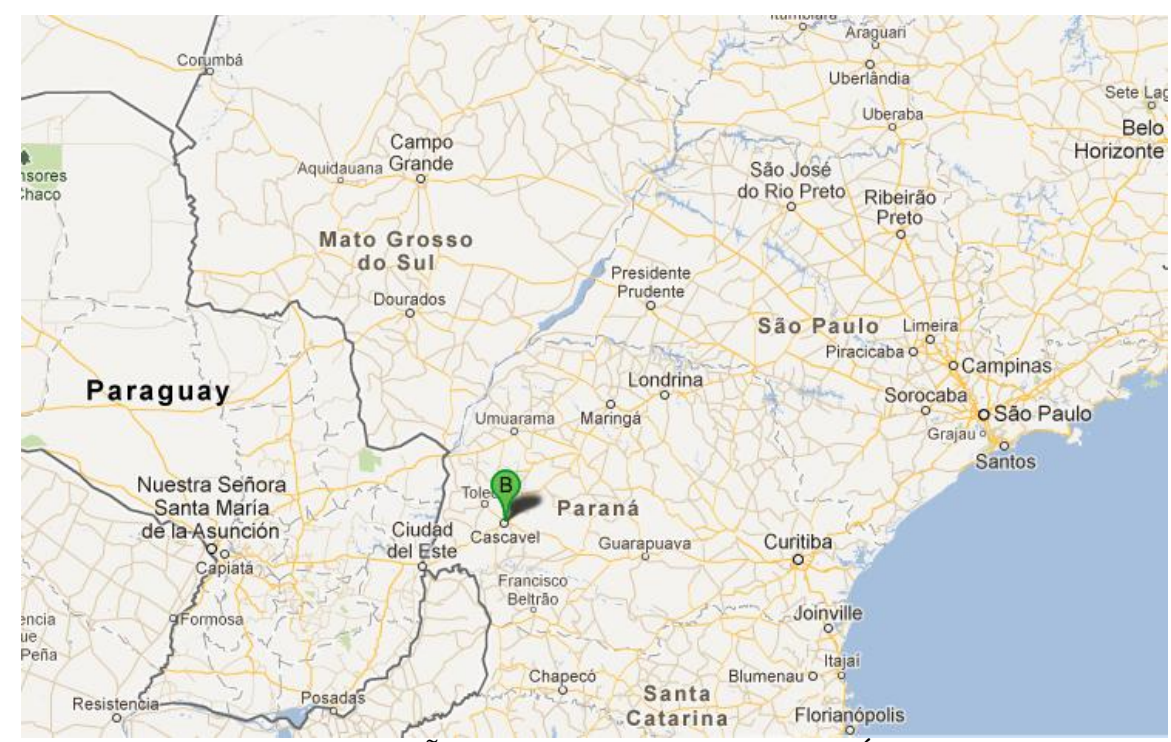

FIGURA 1 - LOCALIZAÇÃO DE CASCAVEL NA AMÉRICA DO SUL (ESTADO DO PARANÁ). Fonte: 〈https://maps.google.com.br/maps?hl=pt-BR\&tab=wl>. Acesso em 02/10/2012.

Cascavel conta com importantes vias de acesso rodoviárias, dentre as principais elenca-se a BR 277 que liga a cidade à capital do estado Curitiba, distante 478 km e a um destino turístico com grande importância e destaque no cenário nacional, a cidade de Foz do Iguaçu, distante $145 \mathrm{~km}$. A BR 467 liga Cascavel às cidades da região oeste do estado, como Toledo e Marechal Cândido Rondon e tem acesso, também, à BR 369 que a conecta às cidades do norte paranaense, levando às saídas para o Sudeste e CentroOeste do Brasil. (DER-PR, 2012).

As facilidades de acesso ao município são amplas, além das três rodovias federais na entrada da cidade, pode-se utilizar das diversas empresas de ônibus de transporte rodoviário que operam no município ou então do aeroporto municipal que conta com voos diários às cidades de São Paulo e Curitiba. (EM SAMPA, 2012). Há voos também para a cidade de Maringá, no norte do estado, e cidades das regiões centro-oeste e norte do país, que são bastante utilizados por visitantes dos eventos relacionados ao setor agropecuário. 
Cabe destaque, ainda, à rota do escoamento da produção de grãos, tanto local como regional, por meio da Ferrovia Paraná Oeste - FERROESTE, a qual liga Cascavel à Guarapuava integrando-se à malha ferroviária brasileira a partir daquela cidade. (FERROESTE, 2012).

No âmbito socioeconômico, Cascavel está entre as 100 maiores arrecadações do país levando em conta o PIB - Produto Interno Bruto, sendo que o PIB per capita, ou seja, a riqueza da cidade dividida pelo número de habitantes chega a $\mathrm{R} \$ 16.849,63$ (IBGE, 2010). Segundo a mesma fonte o município detém um Índice de Desenvolvimento Humano de grau elevado, que é de $0,81^{1}$, posicionando Cascavel à frente de outras importantes cidades do estado como Foz do Iguaçu e Ponta Grossa.

\subsection{TURISMO}

Conforme definição da EMBRATUR - Instituto Brasileiro de Turismo:

O turismo é gerado pelo deslocamento voluntário e temporário de pessoas para fora dos limites da área ou região em que têm residência fixa, por qualquer motivo, exceto quando exercer alguma atividade remunerada no local em que visita (EMBRATUR, glossário de turismo on-line).

Também em 1992, Oscar de La Torre definiu a atividade da seguinte forma:

[...] um fenômeno social que consiste no deslocamento voluntário e temporário de indivíduos ou grupos de pessoas que, fundamentalmente por motivos de recreação, descanso, cultura ou saúde, saem do seu local de residência habitual para outro, no qual não exercem nenhuma atividade lucrativa nem remunerada, gerando múltiplas inter-relações de importância social, econômica e cultural (DE LA TORRE apud BARRETTO, 1995, p. $13)^{2}$.

Assim, devido à complexidade da atividade surgem distintas definições, sendo a da OMT - Organização Mundial do Turismo, uma das mais aceitas e utilizadas como respaldo na presente pesquisa, conforme abaixo:

\footnotetext{
${ }^{1} \mathrm{O}$ Índice é uma medida comparativa usada para classificar os países pelo seu grau de desenvolvimento humano levando em consideração dados de expectativa de vida ao nascer, educação e PIB per capita recolhidos a nível nacional. Disponível em: <http://www.pnud.org.br/IDH/DH.aspx?indiceAccordion=0>. Acesso em: 08/10/2012.
}

${ }^{2}$ DE LA TORRE, O. El turismo, fenómeno social. México, Fondo de Cultura Económica, 1992. 
O turismo inclui tanto o deslocamento e as atividades realizadas pelas pessoas durante suas viagens e estadas, bem como, as relações que surgem entre eles, em lugares distintos de seu ambiente natural, por um período de tempo consecutivo inferior a um ano e mínimo de 24 horas (pernoite no destino), principalmente com fins de lazer, negócios e outros (OMT, 2003).

Logo, percebe-se que as principais características presentes nas definições é a de ocorrência de um pernoite fora do local de residência, que não seja incentivado por remuneração, que pode ser gerado por várias motivações. Devido a essas diferenças de necessidades dos indivíduos e por promover intrinsecamente diversas relações, a atividade pode ser interpretada como um fenômeno de experiências vividas de maneiras e desejos diferentes por parte dos seres envolvidos, tanto pelos ditos turistas quanto pelos empreendedores do setor (PANOSSO NETTO; ANSARAH, 2009).

Atualmente, em 2013, o fenômeno está associado ao consumo e o seu desempenho é fortemente influenciado pelo crescimento do nível de renda que os consumidores vêm experimentando e adquirindo. Entre os anos de 2000 e 2008 as viagens internacionais cresceram 4,2\% ao ano e alcançaram o total de 922 milhões de turistas no mundo em 2008. (MINISTÉRIO DO TURISMO, 2009). Essas viagens geraram uma renda de aproximadamente cinco trilhões de dólares conforme os dados estatísticos e indicadores do turismo mundial publicados pela Organização Mundial do Turismo. (OMT, 2009).

No Brasil, o setor movimenta cerca de $4 \%$ do PIB e emprega 7,2 milhões de pessoas e poderá alcançar em 2014, ano de realização da Copa do Mundo no Brasil, mais dois milhões de empregos no setor, entrada de $\mathrm{R} \$ 8,9$ bilhões em divisas internacionais e ainda aumentar os desembarques domésticos de 56 milhões, registrados em 2009, para aproximadamente 73 milhões em 2014 (ABDE, 2012; PLANALTO 2012), projetando o Brasil a um lugar de destaque no cenário econômico mundial e consolidando o país como um destino ímpar não somente para o lazer, mas também para a organização de grandes eventos. (OMT, 2009).

Sendo assim, devido à importância que a atividade confere aos indivíduos enquanto visitantes na condição de turistas é necessário atentar para a preparação das pessoas envolvidas na receptividade do visitante, bem como na organização do trade turístico das cidades e na qualidade dos serviços que venham a utilizar como táxis, restaurantes, serviços de informações, agências de viagens, hotéis, entre outros. 
Além disso, vale destacar também que o turismo não traz apenas benefícios econômicos, mas também alterações sociais e ambientais nas localidades em que ocorre, como por exemplo, maior produção de lixo, aumento da quantidade de filas e no fluxo de trânsito, maior poluição visual, devido às propagandas de eventos e informações importantes aos turistas, o que leva aos gestores preocuparem-se com a boa organização na base da cadeia para que a atividade se consolide de maneira responsável para que não se expanda de maneira desenfreada e desordenada.

Todos esses são fatores importantes para o sucesso no desencadeamento da atividade turística de forma a não surpreender negativamente a moradores locais, oportunizando então, uma boa hospitalidade por parte dos munícipes. Afinal, pouco adianta obter-se boa estrutura, qualidade no atendimento e serviços prestados se a população local não estiver preparada para recepcionar esse tipo de visitante.

\subsection{O TURISMO DE NEGÓCIOS E EVENTOS}

De acordo com Panosso Netto e Ansarah (2009, p. 36), o Turismo de Negócios e Eventos pode ser definido como:

[...] o conjunto de atividades que resultam em viagens sob responsabilidade de uma pessoa jurídica - empresa, órgão público, entidade de classe ou ONG - que absorve todas as despesas previstas em sua política de viagem e se preocupa com outros aspectos como segurança, saúde, bem-estar do viajante, com intenção de garantir sua produtividade enquanto esteja fora do seu local habitual de trabalho.

Assim, dentro do contexto explanado no tópico anterior e com a definição acima, o turismo de eventos caracteriza-se pelo deslocamento de pessoas que vão a um determinado local a trabalho ou então, a fim de participar de algum evento. De acordo com a EMBRATUR noticiado em site da prefeitura de Florianópolis, as cidades de São Paulo, Rio de Janeiro, Brasília e Florianópolis são as cidades que revelam maior potencial para esse tipo de atividade turística no Brasil. (FLORIANÓPOLIS, 2012).

O país figura no sétimo lugar no ranking mundial entre os países que mais sediaram eventos no mundo em 2011, ao todo o país sediou 304 eventos classificados 
como internacionais, o que representou um crescimento de $10 \%$ em relação ao ano anterior, quando foram realizados 275 eventos $^{3}$.

Observa-se então uma promissora área dentro do setor de turismo, pois:

[...] as despesas de viagens de negócios brasileiros vão crescer de 9,3\% em 2012 para 30,1 bilhões dólares e mais 12,6\% em 2013; o Brasil está a caminho de ultrapassar a Coreia do Sul, no $8^{\circ}$ lugar em gastos de viagens de negócios, no ranking mundial, ainda em 2012; a previsão de crescimento deve alcançar $6 \%$ na hotelaria; as futuras construções de hotéis serão incentivadas ainda mais pelas próximas Copa do Mundo e Olimpíadas, a demanda ainda vai exceder a oferta; em geral o de despesas de viagens de negócios brasileiro deve ampliar mais rapidamente enquanto a economia global ainda se recupera e as despesas de viagens de negócios brasileiro é fortemente gerado pelos gastos domésticos (80\%), mas em 2012 as taxas de crescimento nas viagens de negócios internacionais serão o dobro das de viagens domésticas. (GBTA - Global Business Travel Association, apud MERCADO DE EVENTOS, 2012). ${ }^{4}$

Além disso, conforme estudo da demanda do turismo internacional no Brasil, realizado pelo Ministério do Turismo no ano de 2011 (Estudo da demanda turística internacional 2004-2010) e (Dados Gerais do Estado Paraná 2006-2011, 2012), 46\% dos turistas estrangeiros que vieram ao país, foram motivados pelo lazer e 23,3\% vieram devido a negócios e convenções, sendo que estes deixaram no país cerca de 120 dólares por dia, no ano de 2010 (MINISTERIO DO TURISMO, 2010b; MINISTERIO DO TURISMO, 2011), firmando o segmento na segunda posição da demanda internacional no Brasil (SETU, 2012; MINISTERIO DO TURISMO, 2012).

As pesquisas estatísticas levantadas pela Secretaria Estadual de Turismo 2011 (Dados Gerais do Estado Paraná 2006-2011, 2012) mostram que o fluxo de turistas no estado vem aumentando a cada ano, chegando a 3,8 bilhões de dólares em total de receitas no ano de 2011, o gasto médio do turista no estado foi de 72,5 dólares no mesmo ano e sua permanência média vem crescendo no período de 2006 a 2011 de 2,5 dias para 4 dias. ${ }^{5}$ (SETU, 2012).

\footnotetext{
${ }^{3}$ Disponível em: <http://portal.pmf.sc.gov.br/noticias/index.php?pagina=notpagina\&noti=6937〉. Acesso em 2012.

${ }^{4}$ Estudo da GBTA veicula notícia. Disponível em: <http://www.mercadoeeventos.com.br/site/noticias/view/89121>. Acesso em: 02/10/2012.

${ }^{5}$ Conforme Dados Gerais do Estado Paraná 2006-2012, 2012, divulgado em:

<http://www.turismo.pr.gov.br/arquivos/File/estatisticas_2012/DadosParana2006_2011.pdf>. Acesso em: 26/10/2012.
} 
Com base nessas informações, destaca-se que o mercado do turismo é promissor no estado do Paraná e, devido à procura pela celebração de grandes eventos, Cascavel tem potencial para aproveitar a crescente demanda desse segmento do turismo para proporcionar um crescimento à sua economia e à sociedade.

Um dos exemplos do fato de que o turismo de negócios e eventos é um viés a se encaixar com a realidade da cidade de Cascavel, está em um dos grandes eventos realizados na cidade que tem repercussão mundial: o Show Rural da Coopavel, uma feira do agronegócio que lança grandes inovações tecnológicas para o mundo da agricultura (CASCAVEL, 2012b), devido à vocação do estado do Paraná no cultivo de grãos, sendo atualmente conhecido como celeiro do Brasil face à sua liderança nacional na produção de grãos ${ }^{6}$.

\subsection{O TURISMO NA CIDADE DE CASCAVEL}

O setor de Turismo na cidade de Cascavel está ligado, administrativamente, à SEMDEC - Secretaria Municipal de Desenvolvimento Econômico, a qual em seu organograma contém o DPETUR - Departamento de Eventos e Turismo, e também pelo COMTUR - Conselho Municipal de Turismo, criado juntamente com o FUMTUR Fundo Municipal para o Turismo pela lei 5.615/2010 (SEMDEC, 2012). O Departamento de Eventos e Turismo tem por responsabilidade organizar e centralizar as informações inerentes aos eventos de grande porte realizados na cidade a fim de divulgar os atrativos de Cascavel para fortalecer seu potencial turístico. (SEMDEC, 2012)

O COMTUR é o órgão deliberativo, propositivo, orientador e fiscalizador com a finalidade de assegurar a participação da comunidade na elaboração e implementação de políticas públicas voltadas ao setor de turismo, e é composto por representantes da comunidade e ligados às entidades e órgãos que visam o desenvolvimento turístico do município como: AMOP - Associação dos Municípios do Oeste do Paraná, CEEP Centro Estadual de Educação Profissional Pedro Boaretto Neto, Sindicato dos Hotéis, Bares, Restaurantes e Similares do Oeste do Paraná, ACIC - Associação Comercial e Industrial de Cascavel, dentre outros. (SEMDEC, 2012)

\footnotetext{
${ }^{6}$ Disponível em: http://www.advivo.com.br/blog/luisnassif/parana-ainda-o-celeiro-do-brasil apud IBGE 2010. Acesso em: 25/09/2010.
} 
A infraestrutura turística da cidade conta, em 2013, com 28 agências de turismo cadastradas na prefeitura municipal, sendo que todas elas operaram com o turismo emissivo, ou seja, comercializam pacotes turísticos nacionais e internacionais, 29 hotéis, os quais totalizam 2917 leitos, 10 motéis, apenas 1 pousada e 6 locadoras de veículos (SEMDEC 2012). A cidade conta, também, com oito pontos turísticos: o Lago Municipal, A Catedral Nossa Senhora da Aparecida, o ateliê do escultor Dirceu Rosa, reconhecido internacionalmente, Fonte dos Leões, Igreja do Lago, Kartódomo, Parque Ambiental e Zoológico Municipal.

\subsection{OS EVENTOS DA CIDADE DE CASCAVEL}

Ao longo de todo o ano ocorrem pelo menos oito eventos que movimentam aproximadamente 10 mil pessoas na cidade, os quais encontram-se listados abaixo, detalhando o número aproximado de visitantes em cada edição e a quantidade de dias de duração (CASCAVEL, 2012a):

- FERCALCE - Feira Regional de Calçados e Acessórios, lançada em 2004, na cidade de Foz do Iguaçu, é realizada em Cascavel desde o ano de 2007 devido a facilidade de acesso à cidade com as diversas regiões do estado. A feira é promovida pela Associação dos Representantes Comerciais de Calçados, Acessórios e Artigos Esportivos do Paraná e está consolidada como a maior feira do setor do estado e tem crescido a cada ano unindo mais de 80 expositores de calçados, acessórios e artigos esportivos do Brasil. Em média o evento recebe aproximadamente 4 mil visitantes que costumam ficar de dois a três dias na cidade. (FERCALCE, 2012).

- O Show Rural da Coopavel é promovido pela Cooperativa Agroindustrial Coopavel e tem como objetivo difundir tecnologias voltadas ao aumento de produtividade de propriedades rurais. No ano de 2012 a feira teve 197.906 visitantes, e reuniu 406 expositores e aproximadamente 4.800 experimentos. $\mathrm{O}$ evento é conhecido mundialmente pelas inovações tecnológicas lançadas, uma vez que muitas companhias deixam para fazer o lançamento de produtos no evento. Atualmente o Show Rural conta com 5 dias de duração e funciona como uma vitrine tecnológica que facilita o acesso de produtores rurais a equipamentos e técnicas que auxiliam a produzir mais e melhor. (SHOW RURAL, 2012). 
- FECOM, a Feira de Comércio de Cascavel acontece anualmente em dois dias e conta com aproximadamente 50 mil visitantes por dia e movimenta aproximadamente 3 milhões de reais em negócios (LIQUIDA CASCAVEL, 2012).

- Cascavel Moto Fest é um encontro de motociclistas promovido pelo clube da cidade denominado Minhocas do Asfalto e, desde o ano de 2009, vem reunindo em média 15 mil visitantes por ano durante os três dias de evento, são aproximadamente 6 mil motociclistas representando em torno de 120 motoclubes. (MINHOCAS DO ASFALTO, 2012).

- Superoeste - A Feira e convenção Regional de Supermercados promovida pela APRAS - Associação Paranaense de Supermercados - reuniu no ano de 2012 durante os dias 10 e 11 de Setembro aproximadamente 7 mil pessoas e movimentou em torno de cinco milhões de reais em infraestrutura, hospedagem, passagens, mão de obra entre outros. O objetivo da feira é reunir supermercadistas e fornecedores para negociações e estreitamento de relações, a cada ano a feira vem aumentando o número de visitantes e promovendo um número maior de negociações (APRAS, 2012).

- Festa das colônias - A tradicional festa é promovida pela catedral da cidade e ocorre no mês de outubro, reunindo barracas com comidas típicas de diversas etnias. Este evento é direcionado ao público local, porém, desperta o interesse de visitantes das cidades vizinhas como Toledo, Santa Tereza e Marechal Cândido Rondon, com uma média de visitantes de 50 mil pessoas para os 3 dias de festa (GUIA CUCA, 2012).

- Congresso Desperta Paraná - Congresso realizado pela OPEVEL, Ordem dos Pastores Evangélicos de Cascavel, reúne o público de igreja evangélicas da região e de diversos lugares do Brasil e até de outros países a fim de ver preletores e cantores renomados no mundo gospel. O congresso acontece durante três dias, entre os meses de Setembro e Outubro e reúne em cada edição aproximadamente 10 mil pessoas (OPEVEL, 2012).

- Expovel - Exposição Feira Agropecuária, Comercial e Industrial de Cascavel é um dos eventos mais importantes do agronegócio do sul do Brasil, reunindo expositores, tecnologias e atrações como rodeios, shows, leilões e gastronomia variada. A feira acontece em 10 dias, costumeiramente no mês de novembro e a expectativa de visitantes fica em torno de 300 mil pessoas (EXPOVEL, 2012). 
Além dos eventos listados acima, vale ressaltar que no ano de 2012 foram realizados, ainda, uma etapa da Stock Car, que atraiu 34 mil visitantes (STOCKCAR, 2012) e da Fórmula Truck, com público de aproximadamente 50 mil pessoas (JORNAL HOJE, 2012), os quais voltaram a acontecer na cidade após 5 anos e tiveram repercussão na mídia nacional. Ainda neste ano aconteceram duas etapas do moto 1000 GP que contou com a participação de aproximadamente 10 mil visitantes. (CGN, 2012).

\section{ANÁLISE E INTERPRETAÇÃO DOS DADOS}

Por meio de dados apresentados pode-se afirmar que comprovam a crescente demanda do segmento de turismo de negócios e eventos no Brasil e no mundo. Quanto aos eventos realizados em Cascavel e sua expectativa de visitantes em cada um dos eventos e pelo levantamento das informações sobre a gestão do turismo na cidade chega-se aos seguintes fatos:

- Observa-se que no ano de 2012, até o mês de outubro, a cidade recebeu cerca de 720 mil visitantes durante os eventos que promoveu, ou, um total de 650 mil visitantes, excluindo-se o público presente na Fórmula Truck e Stock Car, que são eventos que não seguem um calendário fixo e há possibilidades de não ocorrer continuamente;

- Supondo-se que $80 \%$ desse público de 650 mil pessoas sejam residentes na cidade, têm-se um restante de aproximadamente 130 mil pessoas (20\%), que podem ser considerados de turistas de negócios e eventos, para utilizarem uma infraestrutura que conta com aproximadamente três mil leitos (CASCAVEL, 2012c), revelando que a cidade não possui uma infraestrutura de hospedagem suficiente.

- Durante sete meses do ano a cidade promove eventos, o que torna possível a garantia de ocupação nos hotéis com uma permanência mínima desejável ao longo de todo o ano e não sazonalmente, como ocorre em cidades litorâneas, onde em princípio, a lotação ocorre nos meses de temporada de verão. No gráfico abaixo, observa-se os meses em que ocorrem picos de visitação na cidade: 


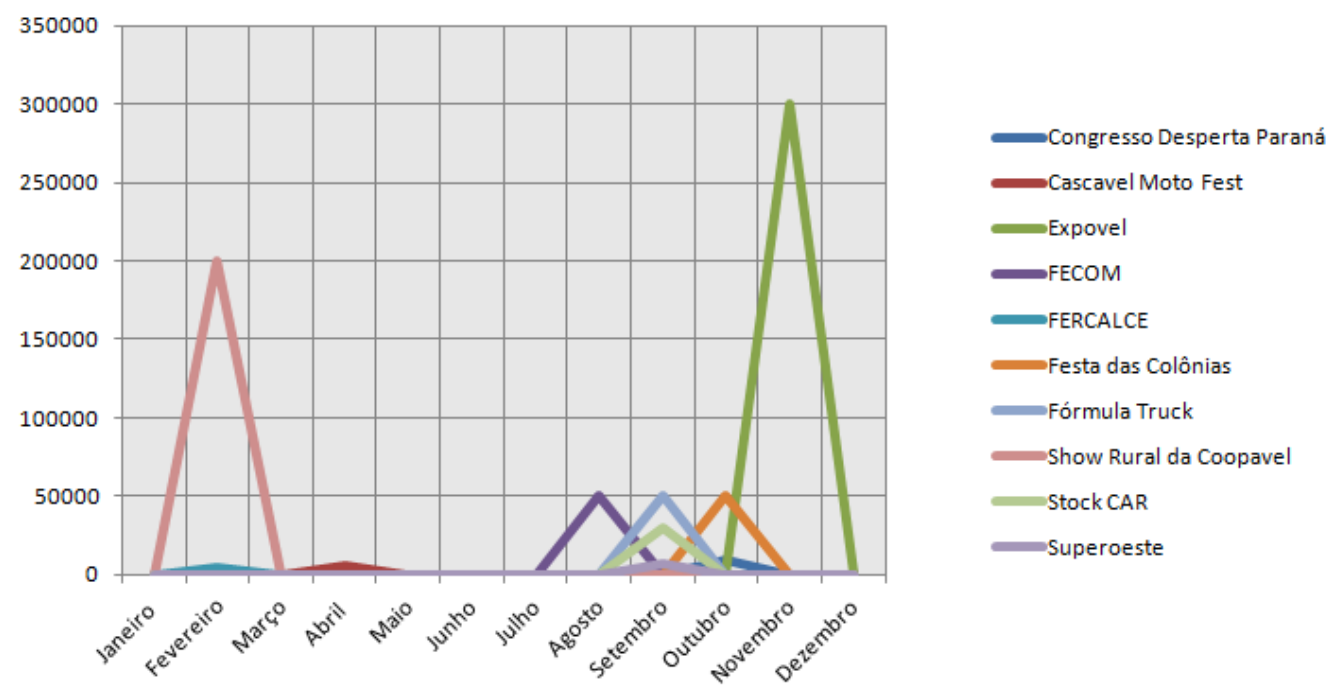

GRÁFICO 1 - EVENTOS EM CASCAVEL DURANTE O ANO Fonte: $\mathrm{O}$ autor. 2012.

Assim, observa-se haver grandes picos de visitantes em Cascavel nos meses de Fevereiro e Novembro, no entanto nos demais meses permanece estável e nos meses de Maio, Junho e Julho não ocorrem grandes eventos no município que levem à necessidade de maior oferta de equipamentos e serviços turísticos. Sendo assim, podemse elencar alguns pontos importantes da presente pesquisa:

- Conforme referenciado anteriormente, de que o visitante gasta aproximadamente 120 dólares por dia em cada evento realizado, e que o visitante fica no mínimo dois dias na cidade obtém-se aproximadamente $\mathrm{R} \$ 500,00^{7}$ que entram na economia da cidade por visitante de evento;

- Em aproximadamente 32 dias ao longo do ano ocorrem eventos em Cascavel, ou seja, considerando que cada visitante gaste 120 dólares na cidade, são R $\$ 7.795,20$ $\left(\mathrm{U} \$ \mathrm{D}\right.$ X $\left.32=\mathrm{U} \$ \mathrm{D} 3.840 \times \mathrm{R} \$ 2,03^{8}\right)$ que a cidade arrecada por pessoa durante o ano. $\mathrm{O}$ que totalizaria $\mathrm{R} \$$ 1.013.376000 - um bilhão, treze milhões, trezentos e setenta e seis mil reais - a mais na economia da cidade (130 000 visitantes $=20 \%$ de todos os visitantes de todos os eventos X R \$ 7.795,20).

- Considerando que a cidade possui, em um raio de $150 \mathrm{~km}$, atrativos turísticos como o Parque Nacional do Iguaçu que abriga as Cataratas do Iguaçu; a Usina Hidrelétrica de Itaipu, praias artificiais em torno no Lago da Hidrelétrica de Itaipu;

\footnotetext{
${ }^{7}$ Utilizando a taxa de conversão do dólar a R \$ 2,035 conforme:

<http://www.bmfbovespa.com.br/home.aspx?idioma=pt-br>. Acesso em: 03/10/2012.

8 Idem.
} 
cidades tipicamente alemãs que dispõem de uma gastronomia diversificada como Missal e Marechal Cândido Rondon, é possível informar e convidar o visitante dos eventos que ocorrem em Cascavel para também conhecer outros atrativos turísticos da região.

- É possível também comunicar ao visitante da cidade que países como Paraguai e Argentina por meio das cidades fronteiriças de Ciudad del Este e Puerto Iguazu, respectivamente, são destinos de compras e que se pode ir até esses locais rapidamente em busca de artigos eletrônicos, de luxo e de última geração, além de uma série de outras atividades advindas destas que complementam e fortalecem o potencial da região oeste do Paraná.

Após a constatação dos pontos elencados acima, observa-se que há oportunidades de crescimento para a área de Turismo na cidade, visto que o mercado é crescente e carente de uma oferta de serviços ao turista, principalmente o de negócios e eventos.

Faz-se necessário também avaliar se os serviços compreendidos desde a saída da residência do turista até seu retorno estão de acordo com a expectativa que este tem ao deixar o conforto da sua moradia para participar de um evento na cidade de Cascavel, como a quantidade e frequência de voos ofertados para a cidade, os serviços de táxi local, bem como a qualidade de atendimento por parte dos taxistas, estruturação de empresas de receptivo turístico, que possa ofertar serviços de transfer, que se observou estar defasado, dentre outras situações cabíveis ao segmento.

\section{CONSIDERAÇÕES FINAIS}

No contexto demonstrado na pesquisa observa-se que ocorre um despertar para o segmento do Turismo denominado de negócios e eventos no Brasil face à projeção econômica que o país vem alcançando. A cidade de Cascavel deve aproveitar o momento em que se consolida como detentora da realização dos eventos aqui vistos, sua localização geográfica próxima a pontos turísticos importantes do estado e, por sua pujança e representatividade econômica para o estado, a fim de fortalecer sua economia no viés que o setor que mais cresce no mundo lhe proporciona. 
Toda a percepção advinda da análise de sua infraestrutura, potencial de empresas que atuam envolvidas no processo de atendimento desta crescente demanda de visitantes de eventos, da maneira como o mercado do Turismo vem atuando crescentemente e, por sua vez, criando condições para atração de potenciais turistas mais exigentes servirá para um novo olhar aos eventos, criando assim oportunidades de uma inovação da maneira como vem acontecendo o turismo no âmbito local.

Contudo, a análise deve ser breve, uma vez que a cidade já conta com uma grande demanda de visitantes e uma pouca oferta de serviços que supram suas necessidades. Este é o momento de observar a infraestrutura que a cidade possui, como está a mão de obra disponível nessa infraestrutura e quais as expectativas de captação de eventos a fim de que o poder público e as empresas atuantes em todas as áreas envolvidas no seu contexto possam se preparar e traçar novos objetivos e metas, levando Cascavel a um lugar de maior destaque no mercado do turístico, podendo então aumentar sua capacidade de captação de eventos de grande porte.

Com essa pesquisa é possível também, obter informações importantes que servem de base para pesquisas mais aprofundadas e uma análise da estrutura organizacional pública de administração do setor, levando em consideração sua adequação ao panorama apresentado, possibilitando, também, um olhar mais apurado ao setor na cidade, despertando novos investimentos, estrutura e profissionalização do setor.

\section{REFERÊNCIAS}

ABDE - Associação Brasileira de Instituições Financeiras de Desenvolvimento. Oportunidades do Turismo no Centro Oeste. In: Workshop ABDE Centro Oeste, 2012, Brasília. Disponível em:

<http://www.abde.org.br/uploads/3011201120113743Turismo.pdf>. Acesso em: 07/10/2012.

APRAS - Associação Paranaense de Supermercados. Disponível em: <http://www.apras.org.br/superoeste/>. Acesso em 24/10/2012.

BARRETTO, M. Manual de Iniciação ao estudo do turismo. Campinas: Papirus, 1995. 
BOLSA DE VALORES DE SÃO PAULO. Disponível em: <http://www.bmfbovespa.com.br/home.aspx?idioma=pt-br>. Acesso em: 03/10/2012.

CASCAVEL A. Disponível em:

< http://www.cascavel.pr.gov.br/noticia.php?id=17637>. Acesso em: 07/10/2012.

CASCAVEL B. Disponível em:

<http://www.cascavel.pr.gov.br/historia.php>. Acesso em: 07/10/2012.

CASCAVEL C. Disponível em:

$<$ http://www.cascavel.pr.gov.br/secretarias/semdec/sub_pagina.php?id=242>. Acesso em: $24 / 10 / 2012$.

CGN - Central Globo de Notícias. Disponível em:

$<$ http://cgn.uol.com.br/noticia/28746/evento-supera-expectativas-e-em-2013-deveretornar-a-cascavel>. Acesso em: 24/10/2012.

DER-PR - Departamento de Estradas e Rodagens do Estado do Paraná. Disponível em: <http://www.der.pr.gov.br/arquivos/File/malha_distancia.pdf>. Acesso em 24/10/2012.

EMBRATUR - Instituto Brasileiro de Turismo. Glossário de turismo on-line. Disponível em:

<http://www.dadosefatos.turismo.gov.br/dadosefatos/espaco_academico/glossario/detal he/T.html>. Acesso em 26/11/2012.

EM SAMPA. Disponível em:

<http://www.emsampa.com.br/voos/aeroporto_cascavel.htm>. Acesso em 24/10/2012.

EXPOVEL. Disponível em: <http://www.expovel.com.br/feira.html>. Acesso em $24 / 10 / 2012$.

FERCALCE. Disponível em: <http://www.fercalce.com.br/feira.php>. Acesso em: 24/10/2012.

FERROESTE. Disponível em:

$<$ http://www.ferroeste.pr.gov.br/modules/conteudo/conteudo.php?conteudo=55>. Acesso em: 24/10/2012.

FLORIANÓPOLIS. Disponível em:

$<$ http://portal.pmf.sc.gov.br/noticias/index.php?pagina=notpagina\&noti=6937>. Acesso em: 07/10/2012.

GOOGLE. Disponível em:

<http://maps.google.com.br/maps?hl=pt-BR\&tab=wl>. Acesso em: 07/10/2012.

GUIA DO ESTUDANTE. Disponível em:

<http:/guiadoestudante.abril.com.br/blogs/pordentrodasprofissoes/as-5-areas-maispromissoras-para-2012-no-brasil/>. Acesso em: 07/10/2012. 
GUIA CUCA. Disponível em:

<http://www.guiacuca.com.br/evento/festa-das-colonias-cascavel-2012>. Acesso em: 24/10/2012.

IBGE - Instituto Brasileiro de Geografia e Estatística. Disponível em:

<http://www.ibge.gov.br/cidadesat/topwindow.htm?1>. Acesso em: 26/09/2012 e 08/10/2012.

JORNAL HOJE. Disponível em:

<http://www.jhoje.com.br/Paginas/20120805/esporte.pdf >. Acesso em: 24/10/2012.

LIQUIDA CASCAVEL. Disponível em:

<http://www.liquidatudocascavel.com.br/site/2012/>. Acesso em: 24/10/2012.

MERCADO \& EVENTOS. Disponível em:

<http://www.mercadoeeventos.com.br/site/noticias/view/89121>. Acesso em:

02/10/2012.

MINHOCAS DO ASFALTO. Disponível em:

<http://www.minhocasdoasfalto.com.br/cascavel-motofest>. Acesso em: 24/10/2012.

MINISTÉRIO DO TURISMO 2009. Disponível em:

<http://www.dadosefatos.turismo.gov.br/export/sites/default/dadosefatos/estatisticas_in dicadores/downloads_estatisticas/Estatxstica_e_Indicadores_de_turismo_no_Mundo__2009_1_3_.pdf>. Acesso em: 08/10/2012.

MINISTÉRIO DO TURISMO 2010a. Disponível em:

<http://www.turismo.gov.br/export/sites/default/turismo/o_ministerio/publicacoes/down loads_publicacoes/Cartilha-Dados_Turismo-15x21-web.pdf>. Acesso em: 24/10/2012.

MINISTÉRIO DO TURISMO 2010b. Disponível em:

<http://www.turismo.gov.br/export/sites/default/turismo/o_ministerio/plano_nacional/d ownloads_plano_nacional/PNT_2007_2010.pdf>. Acesso em: 24/10/2012.

MINISTÉRIO DO TURISMO 2011. Disponível em:

$<$ http://www.dadosefatos.turismo.gov.br/export/sites/default/dadosefatos/demanda_turis tica/internacional/download_internacional/Demanda_Turxstica_Internacional_-

_Fichas_Sinteses_-_2004-2010.pdf>. Acesso em: 10/10/2012.

MINISTERIO DO TURISMO 2012. Disponível em:

<http://www.turismo.gov.br/export/sites/default/turismo/noticias/todas_noticias/Noticia s_download/Turismo_no_Brasil_2011_-_2014.pdf>. Acesso em: 08/10/2012.

OMT, 2003. Disponível em:

<http://www.dadosefatos.turismo.gov.br/export/sites/default/dadosefatos/estatisticas_in dicadores/downloads_estatisticas/Estatxstica_e_Indicadores_de_turismo_no_Mundo__2009_1_3_.pdf>. Acesso em: 08/10/2012. 
OMT. World Tourism Barometer. Madri, v. 7, n. 2, junho 2009.

OPEVEL. Disponível em: <http://www.opevel.com.br>. Acesso em: 24/10/2012.

PANOSSO NETTO; A.; ANSARAH, M. G. dos R.. Segmentação em Turismo: panorama atual. In: PANOSSO NETTO, A.; ANSARAH, M. G. dos R. Segmentação do mercado turístico. Estudos, produtos e perspectivas. Barueri: Manole, 2009. p. 1944 .

PLANALTO. Disponível em: <http://blog.planalto.gov.br/turismo-mais-empregoscrescimento-e-riquezas-para-o-brasil/>. Acesso em: 08/10/2012.

PNUD - Programa das Nações Unidas para o Desenvolvimento. Disponível em: <http://www.pnud.org.br/IDH/DH.aspx?indiceAccordion=0>. Acesso em: 08/10/2012.

SEMDEC, 2012 - Secretaria Municipal do Desenvolvimento Econômico de Cascavel. Disponível em:

<http://www.cascavel.pr.gov.br/secretarias/semdec/pagina.php?id=379>. Acesso em: 07/10/2012.

SECRETARIA DO ESTADO DE TURISMO 2011. Disponível em:

$<$ http://www.setu.pr.gov.br/arquivos/File/pdf/institucional/planoDeAcoesLivretoSITEO K.pdf>. Acesso em: 26/10/2012.

SECRETARIA DO ESTADO DE TURISMO 2012. Disponível em:

<http://www.turismo.pr.gov.br/arquivos/File/estatisticas_2012/DadosParana2006_2011. pdf>. Acesso em: 24/10/2012.

SHOW RURAL. Disponível em:

<http://www.showrural.com.br/sobre/historia/>. Acesso em: 24/10/2012.

STOCKCAR. Disponível em:

<http://stockcar.globo.com/index.php/calendario/>. Acesso em: 02/10/2012.

Recebido em: 18-12-2012

Aprovado em: 17-01-2013

Turismo \& Sociedade. Curitiba, v. 6, n. 2, p. 345-363, abril de 2013. 